\title{
Effect of Mobile Number Portability Adoption on Consumer Switching Intention
}

\author{
Simon Gyasi Nimako ${ }^{1}$, Benjamin A. Ntim ${ }^{2} \&$ Anthony Freeman Mensah ${ }^{1}$ \\ ${ }^{1}$ Department of Management Studies Education, University of Education, Winneba, Ghana \\ ${ }^{2}$ Department of Innovation and Industrial Partnerships, Accra Institute of Technology, P. O. Box AN 19782, \\ Accra, Ghana \\ Correspondence: Simon Gyasi Nimako, Department of Management Studies Education, University of Education, \\ Winneba, Kumasi Campus, Box 1277, Kumasi, Ghana. E-mail: sim.ekomerce@gmail.com
}

Received: December 10, 2013 Accepted: December 31, $2013 \quad$ Online Published: March 24,2014

doi:10.5539/ijms.v6n2p117 URL: http://dx.doi.org/10.5539/ijms.v6n2p117

\begin{abstract}
The paper proposes a model that helps to explain consumer behaviour towards Mobile Number Portability (MNP) policy and the influence of MNP adoption factors on consumer switching intention process in the telecommunication industry. The proposed model was tested using data from a cross-section of 736 subscribers of six global companies in Ghana's mobile telecommunication industry, where MNP has been introduced. The findings indicate that MNP adoption can positively influence consumer switching. The effects of MNP adoption on switching intention is realised through three main channels; directly through MNP-induced self-efficacy (or switching efficacy) and indirectly through perceived switching costs and attitude towards switching. The proposed model helps explain about $50 \%$ of switching intention. The paper discusses implications of the findings to marketing theory and practice and provides directions for future research. The paper advances our knowledge in the impact of government/industrial policy on consumer behaviour in marketing.
\end{abstract}

Keywords: mobile number portability policy, consumer behaviour, porting, switching behaviour, telecommunication service

\section{Introduction}

The mobile telecommunication industry, globally, has seen a lot of innovations such as the integration of global positioning systems, mobile internet facilities, mobile money and mobile payment facilities, mobile number portability (MNP) policy adoption and implementation, among others. Among the innovations, the MNP appears to be the latest in many developing countries across Africa and the Middle East. The MNP innovation allows mobile subscribers to retain their mobile SIM numbers while changing to use other service providers such as voice calls. MNP facility is intended to enable effective service delivery and provide consumers considerable freedom to switch between and among service providers in an attempt to increase consumer empowerment (Buehler \& Haucap, 2004; Lin, Chlamtac, \& Yu, 2003; Reinke, 1998).

Thus, to the subscriber, MNP means to have the freedom to switch between and among the many service providers for telecom services. According to the National Communiications Authority report (NCA, 2011, p. 15), in Ghana the adoption of MNP

“... requires new modes of thinking and operation across the industry as each new porting request involves a customer, a recipient network, a donor network, a central service provider, and all other networks which must route traffic correctly after the port is completed. This is far more complex than a simple interaction between one network and its customers. "

Therefore, the adoption of MNP by consumers will have important implications for marketing theory and practice in consumer behaviour areas such as switching behaviour.

The problem addressed in this study is two-fold. The first is the need to theoretically understand how MNP adoption factors can positively influence consumer behaviour, and second, is the need to provide practitioners with empirical knowledge for strategic management of MNP policy implementation in mobile telecom industry, especially in emerging country contexts. Theoretically, although consumer adoption has been extensively studied in B2C and B2B contexts (e.g., Hoehle, Scornavacca, \& Huff, 2012; Legris, Ingham, \& Collerette, 2004; Prins, 
Verhoef, \& Franses, 2009; Venkatesh, Morris, Davis, \& Davis, 2003; Venkatesh, Thong, James, \& Xu, 2012), relatively little research work has been done in the area of adoption of MNP innovation (e.g., Buehler \& Haucap, 2004; Lin, Chlamtac, \& Yu, 2003; Reinke, 1998). Moreover, in spite of the growing importance of MNP policy implementation in many emerging economies in Asia, Africa and South America, very few studies have examined only the perceptions of consumers about MNP policy in the mobile telecommunication industry in the African emerging economies contexts (e.g., Abdramon, \& Mejabi, 2012; Larkotey, Ansong, Damoah, \& Abandoh-Sam, 2012; Odunaike, 2010; Tiamiyu \& Mejabi, 2012). There is a void in the literature regarding the influence of MNP adoption on consumer behavioural intentions.

Apart from this void in the extant CSB literature, in many emerging countries in Africa, Asia and South America, there seems to be great implementation challenges with the adoption of the MNP policy by consumers. In Ghana, for example, the NCA (2013, p. 9) reported that some agents of mobile networks attempt to deceive customers who are not well-educated and knowledgeable about the MNP through many dubious behaviours.

Given that the critical goal of MNP policy is to facilitate consumer switching and that more empirical knowledge is needed to manage consumer challenges in the adoption of the policy, it becomes important to research into the factors that influence the consumer adoption of MNP policy and how these factors could affect consumer intention to switch to new service providers. These findings will not only advance our knowledge about the relevance and impact of MNP policy implementation on consumer behaviour, but also it will provide the basis for strategy development for telecommunication management and future government regulations. Therefore, the main purpose of this paper is to assess the extent to which MNP policy adoption factors influence consumer switching intentions in the mobile telecommunication industry.

\section{Literature Review and Conceptual Framework}

\subsection{Overview of MNP Concept and Its Implementation}

MNP is the ability of end-users to retain their telephone numbers when changing service providers, service types or locations (NCA, 2012). MNP has the effect of reducing or removing one of the most significant switching costs for consumers and will encourage competition in the telecommunications industry. Literature points to the usefulness of MNP such as creating a level playing field for small mobile operators and new entrants and providing the ideal opportunity to increase market share (Buehler \& Haucap, 2004; Katka, 2004; Ovum, 2000). Some of the challenges that come with MNP have also been identified including significant increase in churn rates, consumers inability to distinguish between different networks when placing call due to unchanging mobile number prefix, increase in termination and porting charges against consumers (Gans \& King, 2000; Wright, 2002).

This facility has been implemented in many developed and developing countries by enactment of special Acts and legal instruments in both wireline and wireless information systems environments. MNP was first introduced in Singapore in 1997, followed by UK, Hong Kong and the Netherlands in 1999. As of 2013, a number of other countries, especially in America, Europe, Asia, Africa, and across the globe have successfully introduced MNP in their telecom industry (Buehler \& Haucap, 2004; Larkotey, Ansong, Damoah, \& Abandoh-Sam, 2012; Odunaike, 2010; Tiamiyu \& Mejabi, 2012). In Africa, MNP has been implemented in countries such as Egypt, Ghana, Nigeria, Kenya, and South Africa. In West Africa, Ghana was the first to introduce the MNP policy followed by Nigeria.

\subsection{MNP Implementation in Ghana}

On July 7, 2011, the MNP policy was launched in Ghana's mobile telecommunication industry (GMTI), under the auspices of the National Communication Authority and in collaboration with the mobile telecom operators. Currently, there are six mobile telecom brands and operators, namely, MTN of Scancom Ltd, Tigo of Millicom Ltd, Kasapa of Kasapa Telecom, Vodafone of Vodafone Group of Public Limited Companies, Airtel of Airtel Ghana Ltd and Glo of Globacom (NCA, 2013). Mobile Number Portability (MNP) system in Ghana allows mobile subscribers to change from one network to another without changing any part of their mobile number (NCA report, 2013). During the second year of its operation, 817, 202 mobile numbers were successfully ported by customers, representing $1.6 \%$ of the total active mobile numbers in Ghana. According to the report, the majority of customers who have ported have remained on their network to which they ported, and they indicated satisfaction with the process and the choice they made. The rate of success of porting requests submitted rose from $75 \%$ to $82 \%$, with an average porting speed of 5 minutes 25 seconds between 2012 and 2013 .

Untill September 2013, MTN consistently had the greatest loss $(275,963)$ representing $2.19 \%$ of their customer base while Tigo and Vodafone consistently had great gains in porting representing $5.12 \%$ and $1.63 \%$ of their 
customer base respectively. On the key challenges, the report (NCA, 2012, p. 14) informs that some mobile telecom service providers still experience operational and technical problems that are yet to be resolved. In addition, there is low consumer awareness and education of the facility. Apart from this, NCA's (2013, p. 9) report also reveals that some dubious behaviour by agents of mobile networks has continued as they deceive customers who are not well-educated and knowledgeable in many ways about the policy. The study addresses consumer knowledge as a key driver of MNP adoption in the proposed model.

\subsection{Theoretical Framework for MNP Adoption}

Several theoretical frameworks have been developed to explain the interrelated concept of consumer adoption of innovation and use of technology in the extant marketing and information systems literature. This study draws on constructs in existing literature and models of consumer adoption to develop a conceptual framework for MNP adoption factors and their influence on consumers' intentions to switch to new service providers in the mobile telecom industry. The following section provides a brief review of the relevant theoretical models such as: Theory of Planned Behaviour, Technology Acceptance Model, and The Unified Theory of Acceptance and Use of Technology.

\subsubsection{The Theory of Planned Behaviour}

Theory of planned behaviour (TPB) was developed by Ajzen (1991) as an extension of the theory of reasoned action (Ajzen \& Fishbein, 1980; Fishbein \& Ajzen, 1975) due to the original model's limitations in dealing with behaviours over which people have incomplete volitional control. Thus, the TPB was developed to account for conditions where individuals do not have complete control over their behaviour (Ajzen, 1991) by the inclusion of perceived behavioural control in TPB.

This theory provides a framework to the study of attitudes toward behaviours. According to the theory, the most important determinant of a person's behaviour is behavioural intention. The TPB postulates three conceptually independent determinants of intention. The first is the attitude toward the behaviour and refers to the degree to which a person has a favourable or unfavourable evaluation or appraisal of the behaviour in question. The second predictor is a social factor termed subjective norm; it refers to the perceived social pressure to perform or not to perform the behaviour. The third antecedent of intention is the degree of perceived behavioural control which refers to the perceived ease or difficulty of performing the behaviour and it is assumed to reflect past experience as well as anticipated impediments and obstacles. As a general rule, the more favourable the attitude and subjective norm with respect to a behaviour, and the greater the perceived behavioural control, the stronger should be an individual's intention to perform the behaviour under consideration. The relative importance of attitude, subjective norm, and perceived behavioural control in the prediction of intention is expected to vary across behaviours and situations.

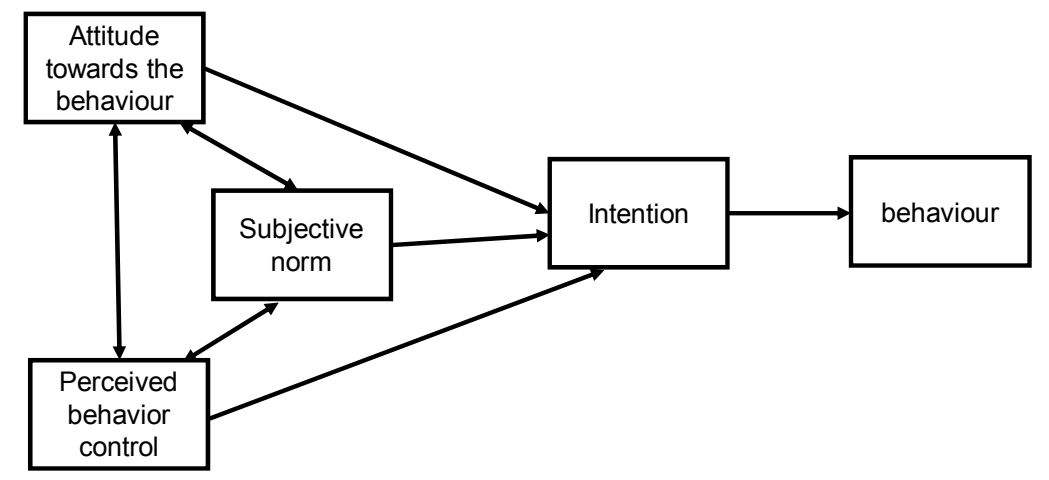

Figure 1. Theory of planned behaviour

The TPB and its constructs have been operationalized and validated in many research contexts (Schlegel, d'Avernas, Zanna, DeCourville, \& Manske, 1990). In spite of the limitations of the TPB, it provides a useful framework for understanding how attitudes, subjective norms, and behavioural control should combine to influence both planned and actual behaviour (Bansal \& Taylor, 1999).

\subsubsection{The Diffusion of Innovation Theory}

The diffusion of innovation theory was proposed by Rogers (1962) to explain the process by which individuals 
adopt innovations and the factors that influence their decision to adoption at different levels. According to Rogers (2003), "An innovation is an idea, practice, or project that is perceived as new by an individual or other unit of adoption" (p. 12). The individual's adoption process involves identified sequence of stages from: (i) an initial knowledge of an innovation, (ii) forming an attitude towards it and (iii) reaching an adoption decision (Rogers, 1962). In the adoption process three types of knowledge play a key role, these are: (1) awareness-knowledge, (2) how-to-knowledge, and (3) principles-knowledge. The author maintains that adoption of innovation is influenced by factors such as relative advantage, compatibility, trailability, observability. Based on this adoption characteristics could be used to classify different adopters into Innovators, Early Adopters, Early Majority, Late Majority and Laggards. In spite of the criticisms it has received, the theory of diffusion of innovation has received widespread application in many research contexts.

\subsubsection{The Technology Acceptance Model (TAM)}

The Technology Acceptance Model (TAM) was developed by Davis, Bagozzi, and Warshaw (1989) to explain the factors that influence individual's adoption and acceptance of a technology. It provides useful foundation for understanding the factors that drive technology acceptance. It has, therefore, been one of the most widely adopted theoretical framework in understanding user acceptance of technology (Bagozzi, 2007). The TAM (see Figure 2) came from Ajzen and Fishbein's (1980). According to the TAM, perceived usefulness and perceived ease of use of the technology in question are hypothesized to be fundamental determinants of user acceptance. The TAM posits that users' actual or behavioural acceptance is principally determined by behavioural intentions to use the technology in question. Behavioural intentions are in turn influenced by the user's attitude towards technology. Davis et al. (1989) maintain that perceived usefulness and perceived ease of use are beliefs that lead to favourable attitudes and intentions to accept and use technology.

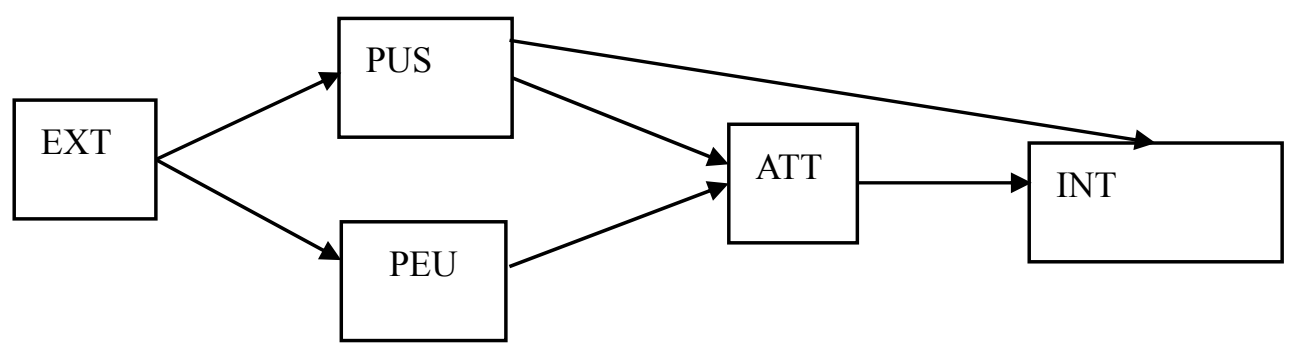

Figure 2. Technology acceptance model (adapted from Davis, Bagozzi, \& Warshaw, 1989)

Note. INT—Intention to Use Technology, ATT—Computer Attitude, PEU—Perceived Ease of Use, PUS—Perceived Usefulness, EXT-External Variables.

Despite the fact that the TAM has been criticized for having attracted a lot of modifications and extensions, which tend to suggest that the model is inadequate to explain technology acceptance in many research context (Bagozzi, 2007), it continues to be empirically proven for its ability to predict about $40 \%$ of a system use (Legris, Ingham, \& Collerette, 2004), and has received praise for its parsimony and predictive powers over the years. The TAM, therefore, could become an important reference theory in understanding the MNP adoption in telecom markets.

\subsubsection{The Unified Theory of Acceptance and Use of Technology (UTAUT)}

Recently, there have been attempts by scholars to combine the TPB, TAM and other similar models into a Unified Theory of Acceptance and Use of Technology (UTAUT) by Venkatesh, Morris, Davis, and Davis (2003). The authors proposed the UTAUT after a thorough review and comparison of eight models, which are the theory of reasoned action, the technology acceptance model, the motivational model, the theory of planned behaviour, a model combining the technology acceptance model and the theory of planned behaviour, the model of PC utilization, the innovation diffusion theory, and the social cognitive theory. The UTAUT was conceptualised as having four core determinants of intention and usage, and up to four moderators of key relationships.

The determinants are performance expectancy, effort expectancy, social influence, and facilitating conditions, which are hypothesized to have significant role as direct determinants of user acceptance and usage behaviour. Moreover, attitude toward using technology, self-efficacy, and anxiety are theorized not to be direct determinants of intention.

The authors noted that all their newly branded proposed constructs had similarities in previous studies. For 
example, the authors admitted that, "The similarities among these constructs have been noted in prior research (Davis et al., 1989; Moore \& Benbasat, 1991; Plouffe et al., 2001; Thompson et al., 1991)" (p. 450). The UTAUT model was found to outperform the eight individual models by predicting behavioural intention by $69 \%$. UTAUT, thus provides a useful tool for managers needing to assess the likelihood of success for new technology introductions.

\subsubsection{The Unified Theory of Acceptance and Use of Technology2 (UTAUT2)}

More recently, the UTAUT has been extended to UTAUT2 by Venkatesh, Thong, James, Xu, (2012). The authors capitalised on the limitations of the former UTAUT and proposed and validated the UTAUT2 using data from 1,512 mobile Internet consumers. The UTAUT2 incorporates three constructs into UTAUT: hedonic motivation, price value, and habit. Individual differences - namely, age, gender, and experience, which are hypothesized to moderate the effects of these constructs on behavioural intention and technology use (Venkatesh, Thong, James $\& \mathrm{Xu}, 2012$ ). Compared to UTAUT, the extensions proposed in UTAUT2 produced a substantial improvement in the variance explained in behavioural intention. Thus, whereas the UTAUT explains 56 percent of behavioural intention and $40 \%$ of technology use, the UTAUT2 predicts $74 \%$ of behavioural intentions and $52 \%$ of technology use.

These recent advances have tried to summarise and extend our knowledge of technology and innovation acceptance and adoption from different industry contexts. Basically, all these models have used the different terminologies for essentially the same constructs. Therefore, the choice of model to use may depend on the research problem, research context and the researcher's preferences.

\subsection{Linking MNP Adoption to Consumer Switching Process}

The theoretical relationship between MNP adoption and CSB could be traced to consumer empowerment provided by MNP. Fundamentally, MNP policy implementation provides the opportunity to switch, serves as an essential tool and resource to switch, and a facilitating condition that influences consumers' belief in their ability to switch. This belief power to switch is also described as perceived behavioural control in Ajzen (1991) or self-efficacy which is an antecedent to behavioural intentions (Ajzen, 1991). In this regard, Ajzen (1991, p. 184) noted that "The present view of perceived behavioural control, however, is most compatible with Bandura's (1977, 1982) concept of perceived self-efficacy which 'is concerned with judgments of how well one can execute courses of action required to deal with prospective situations' (Bandura, 1982, p. 122)" (Ajzen, 1991, p. 184).

In addition to MNP-induced self-efficacy affecting perceived switching intention, other factors identified in the literature (e.g., in TPB, TAM, UTAUT) such as perceived ease of use, perceived adoption costs, perceived usefulness of MNP, peer influence, consumer knowledge of MNP, attitude towards MNP, attitude towards switching and perceived switching cost could play significant role in influencing consumer switching intentions in telecommunication industry. These are included in the conceptual framework for this study.

\subsection{Research Model and Hypotheses}

Based on the literature review and a preliminary focus group interview conducted to clarify the factors that influence the adoption MNP in the research context, a research model was developed (see Figure 3). In the

research model, there are five key factors that could influence MNP adoption, namely, perceived ease of use or perceived adoption costs, perceived usefulness of MNP, consumer knowledge of MNP, attitude towards MNP and perceived MNP-induced self-efficacy. Moreover, there are two antecedents to switching intentions that serve as channels through which MNP adoption factors could affect switching intentions, namely: attitude towards switching and perceived switching cost. We now define each construct in the context of the research problem and establish the hypothesized relationships among the constructs in the research model for empirical testing. The proposed model did not consider intention to port because it sought to examine actual porting behaviour and its determinants, and not intentions to port. 


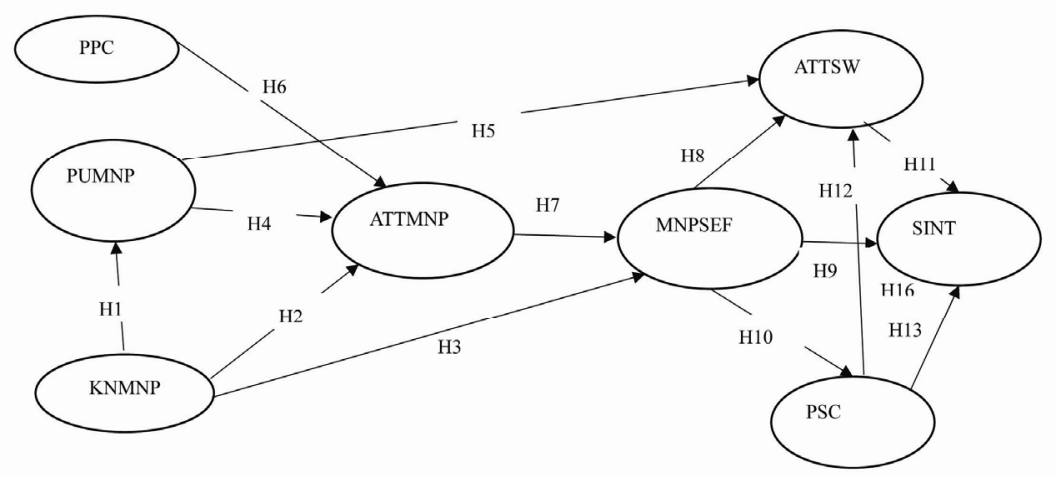

Figure 3. Research model and hypothesized relationships

Note. Consumer knowledge of MNP (KWMNP), Perceived Usefulness of MNP (PUMNP), Perceived Porting Costs (PPC), Attitude towards MNP (ATTMNP), MNP-induced Self-Efficacy (MNPSEF), Attitude towards switching (ATTSW), Perceived switching cost (PSC), Switching intention (SINT).

Moreover, social influence was not included in the model because the outcome of the preliminary focus group interview strongly indicated that social or peer influence was not a critical factor, probably because the MNP policy appears to be new in the research context and not well known or understood by many consumers to generate critical social influence.

\subsubsection{Consumer Knowledge of MNP (KWMNP)}

Consumer knowledge of MNP (KWMNP) is defined as the extent to which consumers have adequate information and understanding about MNP policy, its implementation process, its proposed usefulness, its requirements, and consumer responsibility in porting process. Consumer knowledge about innovations and new technology is an essential condition for adoption of an innovation or technology (Rogers, 2003). Cordell (1997) empirically found that consumers' knowledge of the existing product or service category is a leading factor that affects the adoption process. Similarly Marcketti and Shelley (2009) maintained that consumers' knowledge of products has a significantly positive effect on their adopting intentions. More recently, Huang, Hsieh and Chang (2011) found that consumer knowledge was positive factor that influenced the adoption of Location-Based Services. The more consumers' knowledge and understanding of MNP policy and its implementation increase, the more they are likely to understand the perceived benefits or usefulness of MNP, have a favourable attitude towards MNP, have strong belief in their ability to switch (self-efficacy) through MNP, and finally adopt or port their mobile numbers. Therefore, the following hypotheses are postulated:

H1: Consumer level of knowledge of MNP will have significantly positive influence on perceived usefulness of MNP policy.

H2: Consumer level of knowledge of MNP will have significantly positive influence on attitude toward MNP policy.

H3: Consumer level of knowledge of MNP will have significantly positive influence on MNP-induced self-efficacy.

\subsubsection{Perceived Usefulness of MNP (PUMNP)}

Perceived usefulness of MNP (PUMNP) is defined as the degree to which a person believes that porting their mobile number to another mobile network operator will enhance his or her personal well-being or will be beneficial to the society as a whole (Davis, Bagozzi, \& Warshaw, 1989; Legris, Ingham, \& Collerette, 2004). Perceived usefulness of MNP is expected to induce a favourable or positive consumer attitude towards MNP policy, and also affect consumer general attitude towards switching. Therefore, it is hypothesized that:

H4: Perceived usefulness of MNP will have significantly positive influence on attitude towards MNP policy.

H5: Perceived usefulness of MNP will have significantly positive influence on consumer general attitude towards switching.

\subsubsection{Perceived Porting Costs (PPC)}

Perceived porting costs is defined as consumer perception of the sacrifices they have to make into order to start and complete the process of porting their mobile numbers to another network. PPC is based on the understanding 
that the consumer has some responsibility to bear which involves some efforts, financial and non-financial sacrifices which they have to make in porting their mobile number (Gans \& King, 2000; Wright, 2002). Even though in many countries such as Ghana there is no porting fees for consumers, there could be other porting costs such as time, effort, and even money for making calls to or transport fare to go to the designated firm's office to complete the porting process. These perceived poring costs are likely to cause favourable or unfavourable attitude to porting or MNP adoption by consumers. Therefore, it is hypothesized that:

H6: Perceived porting cost will have significantly positive influence on attitude towards MNP policy.

\subsubsection{Attitude towards MNP (ATTMNP)}

Attitude towards MNP refers to the degree to which a person, generally, has a favourable or unfavourable evaluation or appraisal of the MNP policy (Ajzen, 1999). It is well documented in the literature that attitude towards a behaviour strongly and directly predicts actual behaviour in many research contexts (e.g., Ajzen \& Fishbein, 2000, 2005; Lee, Cheung, \& Chen, 2005, Lin \& Lu, 2000; Liu, Liao, \& Peng, 2005; Park, 2009), even though some studies indicate that this relationship may not always be direct (Davis, Bagozzi, \& Warshaw, 1989; Venkatesh, 2000; Venkatesh \& Davis, 2000). It is expected that consumers' favourable or unfavourable attitude towards MNP can affect their self-efficacy to switch (or port). Unfavourable attitude towards MNP policy can negatively affect their self-efficacy. Therefore, it is hypothesized that:

H7: Attitude towards MNP will have significantly positive effect on MNP-induced self-efficacy.

\subsubsection{MNP-Induced Self-Efficacy (MNPSEF)}

Generally, self-efficacy "is concerned with judgments of how well one can execute courses of action required to deal with prospective situations" (Bandura, 1982, p. 122). It is described as the belief in one's ability to be able to perform a given task effectively. Self-efficacy could be likened to the concept of perceived behavioural control (PBC) which refers to the perceived ease or difficulty of performing the behaviour and it is assumed to reflect past experience as well as anticipated impediments and obstacles (Ajzen, 1991). PBC conveys the meaning that people have the necessary resources, abilities, and opportunities to perform such behaviour (Ajzen, 1991; Conner, Warren, \& Close, 2001; Lam \& Hsu, 2006). People's behaviour is strongly influenced by their confidence in their ability to perform it (Ajzen, 1991). Some past studies have drawn attention to internal and external components of PBC (e.g., Kidwell \& Jewell, 2003). In this regard, MNP is perceived to be an externally oriented factor that provides the facilitating condition, resources, and opportunity to induce confidence in consumers' ability to switch. MNP-induced self-efficacy is expected to induce favourable consumer attitude towards switching and have a direct influence on consumer switching intention. Moreover, since MNP is intended to reduce switching barrier or costs, it is expected that switching efficacy will reduce perceived switching cost. Therefore, it is hypothesized that:

H8: MNP-induced self-efficacy will have significantly positive effect on attitude towards switching.

H9: MNP-induced self-efficacy will have significantly positive and direct effect on switching intention.

H10: MNP-induced self-efficacy will have significantly negative effect on perceived switching cost.

\subsubsection{Attitude towards Switching (ATTSW)}

Attitude towards switching refers to the degree to which a person has, generally, a favourable or unfavourable evaluation or appraisal of the idea of switching from one service provider to another (Ajzen, 1999). This is one of the channels through which MNP adoption is expected to affect consumer switching intentions and behaviour. Previous studies have established that attitude is a strong predictor of intention to perform or act (e.g., Ajzen \& Fishbein, 2000, 2005; Liu, Liao, \& Peng, 2005; Park, 2009). It is expected that consumers' favourable or unfavourable attitude towards switching can affect their intention to switch positively or negatively. Therefore, it is hypothesized that:

H11: Attitude towards switching will have significantly positive effect on switching intention.

\subsubsection{Perceived Switching Cost (PSC)}

Perceived switching cost (PSC) refers to consumer perception of the sacrifices they have to make in order to be able to partially or totally switching from one network to another. PSC may be distinguished from perceived porting costs (PPC) in that whereas PPC relates perceived costs associated porting process such as porting fees, time and other financial and non-financial porting efforts, PSC broadly relates to costs such as financial cost (buying new SIM), relationship cost in losing important relationship with firm's staff, loss of one's phone number that uniquely identifies them, having to inform contacts of a number change, cost of time and effort in activating new SIM cards, among others (Buehler, Dewenter, \& Haucap, 2006; Dick \& Basu, 1994). In the 
switching behaviour literature, PSC has been found to be an important factor that affects consumer switching process, intention and behaviour (e.g., Bansal, Taylor, \& James. 2005; Bansal, Irving, \& Taylor, 2004; Keaveney, 1995). Where consumers perceive switching cost to be high, switching intention is more likely be low and where switching cost is low, switching intention will more likely be high as consumers will have high incentive to switch due to low switching barriers. Where consumers' incentive to switch is discouraged by high PSC, it will not only reduce switching intentions, but also cause consumers to stay with and be committed to current service provider as there will be no gains in changing their service provider. In effect PSC becomes one of the channels through MNP adoption can affect consumer switching intentions. Therefore, it is hypothesized that:

H12: Perceived switching cost will have significantly negative effect on attitude towards switching.

H13: Perceived switching cost will have significantly negative effect on switching intention.

\subsubsection{Switching Intention (SINT)}

Switching intention refers to the extent to which a consumer is willing to switch from one service provider to another. Switching intentions to capture the motivational factors that influence a behaviour; they are indications of how hard people are willing to try, of how much of an effort they are planning to exert, in order to perform the behaviour Ajzen (1991). Therefore, since MNP adoption by a consumer indicates a partial intention to switch, it is expected that the motivational factors that affect adoption are likely to ultimately influence consumers' intentions to switch completely to a new service providers, especially by raising attitude towards switching and reducing switching cost. Thus, all the hypothesized relationships are expected to contribute significantly to overall explanation of the dependent variable of consumer switching intentions, to be assessed through the co-efficient of determination $\left(\mathrm{R}^{2}\right)$.

\section{Methodology}

\subsection{Population and Sampling}

The population consisted of 26,591,124 individual subscribers as of April, 2013 (NCA, 2013) from all the six mobile telecommunication operators in Ghana, operating under these brand names: MTN Ghana, Vodafone Ghana, Airtel Ghana, Tigo, Expresso and Glo Ghana. The appropriate sample size was estimated using Yamene's (1967) formula that yielded a minimum sample size of 400. In order to collect data of high quality that reflect customers' opinion and have quality of good representativeness, a survey was conducted from a cross-section of subscribers of mobile telecom service providers across the country in July 2013. The survey yielded a usable 736 questionnaires returned representing $73.6 \%$ response rate for analysis.

To investigate potential non-response bias, we compared responses from early and late respondents (Armstrong \& Overton, 1977). Early respondents were described as the usable questionnaires returned within the first week and late respondents were those who responded in the third week and those who were followed up with telephone call to remind them to return the completed questionnaires. At the $5 \%$ level of significance, no significant differences were observed, thus indicating that response bias was unlikely to be a major problem in the present study.

\subsection{Research Instrument}

A self-administered, structured questionnaire was developed and pre-tested to a sample of twenty (20) customers. Adjustments were made based on the pre-test to get a more effective instrument. After that the questionnaire was finally administered to mobile subscribers through personal contact by researchers for nearly three weeks. Since high predictive validity was a major concern, a five-point Likert scale was used, as recommended in previous work (Danaher \& Haddrell, 1996), to measure variables for the eleven research constructs. The Likert scale ranged from strongly disagree to strongly agree, coded 1 to 5 respectively. In all, the measurement items for the eleven constructs had 31 items that were derived from previous studies and modified within the context of the mobile subscribers in GMTI as shown in Table 1. The questionnaire also contained respondents' demographic data: gender, age, education, income, marital status, and whether customer has ported their mobile number or not.

\section{Results}

\subsection{Respondents' Characteristics}

For the characteristics of the respondents, in terms of gender, $67.7 \%$ of the respondents were males and $32.3 \%$ were females. $20.7 \%$ of the respondents were below 25 years, $67.3 \%$ of them were within the ages of $25-36$ years, $11.4 \%$ were between 37 and 50 years, and .6\% were 50 years and above. This implies that majority of them were in the economically active population. All respondents were educated with about $58.7 \%$ of them 
having tertiary level of education, while about 5\% and 33\% had Senior High School (SHS) and post-SHS education respectively. About 3\% had other forms of education. In terms of income, $33.5 \%$ of respondents earned monthly income up to GH $₫ 500$, while $43.9 \%$ earned between $\mathrm{GH} \phi 500$ and $\mathrm{GH} \phi 1000$, about $6.5 \%$ earned monthly income above GH $\phi 1000$. This indicates that most of them earned considerably low incomes. In terms of marital status, $61.7 \%$ of the respondents were married, about $36 \%$ were single (not married) and about $2 \%$ of them were in other marital category.

\subsection{Method of Analysis for Proposed Model}

Data were analysed using SPSS version 16.0 and Amos version 18.0 to perform Confirmatory Factor Analysis (CFA) and Structural Equation Modelling (SEM) to test the hypothesized relationships among the constructs in the proposed model (Figure 1). Since the study involved testing the relationships among series of separate, but interdependent, multi-dimensional constructs simultaneously, SEM method was the most suitable method to adopt (Hair, Black, Babin, \& Anderson, 2010). A two-stage SEM approach was adopted in analysing the proposed model (Anderson \& Gerbing, 1988), first the reliability and validity of the constructs are assessed, followed by assessment of model fitness and then the path co-efficients of the hypothesized relationships.

Before the CFA, the normality of the data were assessed via the use of scatterplots, normality plots and normality assessment available in AMOS 18.0 and the results indicated that data was considerably normal with Skewness and Kurtosis of items within +/- 1.96 (Razali \& Wah, 2011). The sample size of 736 was deemed appropriate for testing the proposed model since as a rule of thumb a sample of 200 is considered adequate (Hair, Black, Babin $\&$ Anderson, 2010). Covariance-based SEM was chosen because the study focused on model testing.

\subsection{CFA and Model Modification}

To ensure item and construct reliability and validity, the items in the first-order constructs in the proposed model were subject to a CFA using AMOS 18.0 for Windows. The CFA model fit results indicated the following initial fit statistics: $\mathrm{X} 2=2422.549, \mathrm{df}=1137, \mathrm{CMIN} / \mathrm{DF}=2.131, \mathrm{GFI}=.908, \mathrm{AGFI}=.880, \mathrm{CFI}=.943, \mathrm{TLI}=.931$, PCFI $=.769$, RMR $=.072$, RMSEA $=.028$. Following inspection of the factors loadings, three items (LTY3, ATTMNP3 and PPC1) had factor loadings less than .50; consequently these items were removed from further analysis. Since the perceived porting cost (PPC) construct had two items (PPC1 and PPC2), deleting one item meant deleting the construct, too. Further examination of the modification index (MI) and the standardized residuals (SR) suggested that two items (ATTSW3 and CMT3) were problematic in that they had MI greater than 10 and 18 respectively and SR greater than 3 ; so they were removed to improve the model further: $\mathrm{X}^{2}=373.226$, $\mathrm{df}=173, \mathrm{CMIN} / \mathrm{DF}=1.574, \mathrm{GFI}=.968, \mathrm{AGFI}=.953, \mathrm{CFI}=.989, \mathrm{TLI}=.985, \mathrm{RMR}=.029, \mathrm{RMSEA}=.028$.

\subsection{Assessment of Model Reliability and Validity}

For the remaining items in the first-order constructs, item, construct reliability and construct validity were assessed. Reliability refers to the extent to which a measuring instrument yields consistent results under similar conditions (Hair, Black, Babin \& Anderson, 2010). Item reliability was assessed through the factor loadings (see Table 2), which should be equal to or greater than .50 to indicate item reliability (Hair, Black, Babin, \& Anderson, 2010). From Table 2, all the measurement had factor loadings greater than .50 implying that the individual items explain well the variances of the construct they represent (Anderson \& Gerbing, 1988). Moreover, construct reliability was assessed through Cronbach alpha (CA) and Composite Reliability (CR) (see Table 2). The recommended value for Cronbach alpha is .70 or better (DeVellis, 2003). From Table 2, the CA and $\mathrm{CR}$ values are greater than .70, implying acceptable level of reliability for each construct.

Construct validity was assessed through criterion validity, convergent and discriminant validity results (see Table 2). From Table 1, all constructs had strong theoretical background to support criterion validity. Convergent validity refers to how indicators together explain a construct and shows the extent to which each measure correlates with other measures of the same latent construct (Hair, Black, Babin, \& Anderson, 2010). Convergent validity could be assessed through item reliability, composite reliability, and the average variance extracted (AVE) (Fornell \& Larcker, 1981). As already demonstrated in Table 2, item and composite reliabilities are adequate. AVE measures the amount of variance captured by the construct in relation to the amount of variance attributable to measurement error.

Convergent validity is judged to be adequate when AVE equals or exceeds .50. It is estimated as the sum of all the square of factor loadings for a given construct (square multiple correlations) divided by the total number of items measuring the construct (Hair, Black, Babin, \& Anderson, 2010). As shown in Table 2, all the AVE values are greater than .50 , ranging from .520 to .826 . Therefore, taken together, the evidence from the high composite reliability values, high factor loadings, and high AVE estimates provide strong evidence in support of convergent 
validity.

Table 1. Constructs and measurement items

\begin{tabular}{|c|c|c|c|}
\hline Constructs & Code & Measurement items & Source \\
\hline \multirow[t]{2}{*}{ Knowledge of MNP } & KNMNP1 & $\begin{array}{l}\text { How much knowledge do you have about the mobile number portability (MNP) } \\
\text { policy by which you can switch to other telecom networks with an existing } \\
\text { mobile number? }\end{array}$ & $\begin{array}{l}\text { Self-developed based } \\
\text { on Cordell (1997); } \\
\text { Roger (2003). }\end{array}$ \\
\hline & KNMNP2 & To what extent do you really understand how the whole MNP works? & \\
\hline Perceived & PUMNP1 & To what extent do you think the MNP is useful a policy? & Davis et al. (1989); \\
\hline Usefulness of MNP & PUMNP2 & To what extent do you think the MNP will benefit you? & Legris et al. (2004) \\
\hline Attitude towards & ATTMNP1 & I think the idea of MNP policy is ....... & Self-developed based \\
\hline \multirow[t]{2}{*}{ MNP } & ATTMNP2 & I believe adopting the MNP policy is ... & on Lee et al. (2005); \\
\hline & ATTMNP3 & Generally I have positive attitude towards the MNP policy. & Park (2009) \\
\hline \multirow[t]{3}{*}{$\begin{array}{l}\text { MNP-induced Self- } \\
\text { Efficacy }\end{array}$} & MNPSEF1 & $\begin{array}{l}\text { The Mobile Number Portability policy (MNP) can help me to switch easily to } \\
\text { use other mobile network services in Ghana }\end{array}$ & $\begin{array}{l}\text { Self-developed based } \\
\text { on Ajzen (1991); }\end{array}$ \\
\hline & MNPSEF2 & $\begin{array}{l}\text { I belief that in Ghana, with the MNP, now I have every opportunity to switch to } \\
\text { any mobile telecom network I like. }\end{array}$ & $\begin{array}{l}\text { Ajzen \& Fishbein } \\
(2000,2005)\end{array}$ \\
\hline & MNPSEF3 & I belief that with the MNP, I can easily switch to any mobile network I like. & \\
\hline \multirow[t]{2}{*}{$\begin{array}{l}\text { Perceived Porting } \\
\text { Cost }\end{array}$} & PPC1 & $\begin{array}{l}\text { To what extent do you think the process of porting your mobile number is time } \\
\text { consuming? }\end{array}$ & $\begin{array}{l}\text { Self-developed based } \\
\text { on Gans \& King }\end{array}$ \\
\hline & PPC2 & $\begin{array}{l}\text { To what extent do you think the process of porting my XYZ number comes with } \\
\text { inconveniences? }\end{array}$ & $\begin{array}{l}(2000) \text {; Wright } \\
(2002)\end{array}$ \\
\hline \multirow[t]{3}{*}{ Switching intention } & SINT1 & $\begin{array}{l}\text { Do you have the intention of switching to use a better mobile network services } \\
\text { in the next year? }\end{array}$ & $\begin{array}{l}\text { Developed based on } \\
\text { Bansal et al.(2005) }\end{array}$ \\
\hline & SINT2 & $\begin{array}{l}\text { How likely are you to switch from XYZ to a different network in the next two } \\
\text { years? }\end{array}$ & \\
\hline & SINT3 & $\begin{array}{l}\text { Are you considering changing from XYZ to a better mobile telecom network } \\
\text { soon? }\end{array}$ & \\
\hline \multirow{3}{*}{$\begin{array}{l}\text { Attitude towards } \\
\text { switching }\end{array}$} & ATTSW1 & For me switching from one mobile network to another is ... & Venkatesh et al. \\
\hline & ATTSW2 & For me changing from one network to another is a decision that is...... & (2012); Ajzen \& \\
\hline & ATTSW3 & $\begin{array}{l}\text { The idea of changing from one mobile network to another is to me a ....... } \\
\text { attitude. }\end{array}$ & $\begin{array}{l}\text { Fishbein }(2000, \\
2005) \text { etc. }\end{array}$ \\
\hline \multirow[t]{3}{*}{$\begin{array}{l}\text { Perceived switching } \\
\text { cost }\end{array}$} & PSC1 & $\begin{array}{l}\text { I think it would cost me a lot of time and money trying to switch to another } \\
\text { telecom network. }\end{array}$ & $\begin{array}{l}\text { Barroso \& Picón } \\
\text { (2011); Bansal et al. }\end{array}$ \\
\hline & $\mathrm{PSC} 2$ & $\begin{array}{l}\text { Generally, I will lose other important contacts (or relationship benefits) with } \\
\text { staff of service provider if I switch from XYZ to another network. }\end{array}$ & $\begin{array}{l}\text { (2005); } \\
\text { Buehler et al. (2006); }\end{array}$ \\
\hline & $\mathrm{PSC} 3$ & $\begin{array}{l}\text { I think it would cost me a lot of effort trying to switch to another telecom } \\
\text { network. }\end{array}$ & Dick \& Basu (1994) \\
\hline
\end{tabular}

Discriminant validity refers to the extent to which a construct is distinct from other constructs in the research model (Farrell, 2010). At the construct level, discriminant validity is considered adequate when the variance shared between a construct and any other constructs (covariance) in the model is less than the variance which that construct shares with its measures (Farrell, 2010).

As indicated in Table 2, the AVE estimates in the diagonal are greater than the covariance below the diagonal (inter-construct correlations). Therefore, discriminant validity appears satisfactory at the construct level in the case of all constructs. This indicates that each construct shared more variance with its items than it does with other constructs. Since the results show good discriminant validity for the constructs, the constructs in the proposed research model are deemed to be adequate. 
Table 2. Factor loading, AVE, construct reliability and validity

\begin{tabular}{lllllllllll}
\hline Constructs & PSC & MNPSEF & SINT & ATTMNP & ATTSW & PUMNP & KNMNP & AVE & CR & $\boldsymbol{\alpha}$ \\
\hline PSC &. $\mathbf{7 2 1}$ & & & & & & & .520 & .700 & .768 \\
MNPSEF & -.049 & $\mathbf{. 7 6 8}$ & & & & & & .590 & .758 & .798 \\
SINT & .314 & .018 & $\mathbf{. 8 0 9}$ & & & & & .655 & .800 & .829 \\
ATTMNP & .052 & -.233 & .010 & $\mathbf{. 8 1 6}$ & & & & .666 & .815 & .797 \\
ATTSW & .258 & -.025 & .670 & .083 & $\mathbf{. 8 2 1}$ & & & .674 & .810 & .790 \\
PUMNP & .050 & -.291 & .032 & .496 & .098 & $\mathbf{. 8 8 2}$ & & .778 & .795 & .769 \\
KNMNP & -.190 & .383 & .030 & -.182 & -.071 & -.199 & $\mathbf{. 9 0 9}$ & .826 & .905 & .896 \\
Factor Loadings & PSC & MNPSEF & SINT & ATTMNP & ATTSW & PUMNP & KNMNP & & & \\
Item 1 & .803 & .733 & .912 & .850 & .772 & .733 & .822 & & & \\
Item 2 & .734 & .832 & .637 & .780 & .848 & .858 & .988 & & & \\
Item 3 & .649 & .710 & .852 & - & - & - & - & & & \\
\hline
\end{tabular}

Note. All correlations are significant at .01 or .05 , AVE (Average Variance Extracted), Square root of AVE are bold in the diagonal, $\mathrm{CR}$ - Composite reliability, $\alpha$ - Cronbach Alpha.

\subsection{Model Goodness-of-Fit}

In using SEM, in examining the model fitness, the usual method is the use of the chi-square method or the ratio of the chi-square to its degree of freedom, with a value less than three indicating acceptable fit (Hair, Black, Babin, \& Anderson, 2010). However, due to the fact that the chi-square of the default model could be affected by large sample size greater than 250, many researchers recommend a combination of several goodness-of-fit indices for judging fitness of a structural model (ibid). Several benchmarks for good-fit indices have been suggested by many scholars (e.g., Bagozzi \& Yi, 1988; Hair, Black, Babin, \& Anderson, 2010) as shown in Table 3. These authors recommend that a combination of at least one absolute goodness-of-fit measure, one absolute badness-of-fit index, one incremental fit measure and one comparative fit index is required for strong evidence of good model fitness.

In this study, as shown in Table 3, the results show a significant Chi-square which is to be expected due to the large sample size above $250(\mathrm{n}=736)$ as noted in previous work (Hair, Black, Babin, \& Anderson, 2010). All other fit-indices are better than their corresponding recommended values $(\mathrm{GFI}=.964, \mathrm{AGFI}=.953, \mathrm{NFI}=.965$, $\mathrm{CFI}=.986, \mathrm{TLI}=.984, \mathrm{PGFI}=.728, \mathrm{PCFI}=.816, \mathrm{PNFI}=.841), \mathrm{RMR}=.066, \mathrm{RMSEA}=.020$. Therefore, there is good fit for the model. Thus, we proceed to examine the regression co-efficients for the estimated structural model; this is presented in Table 4.

Table 3. Goodness-of-fit indices for structural model

\begin{tabular}{lll}
\hline Goodness-of-fit Indices & Benchmark & Value \\
\hline Absolute goodness of fit measure & & \\
Chi-square (CMIN) & $\mathrm{P} \geq .05$ & .000 \\
Chi-square /degree of freedom & $\leq 3$ & $308.7 / 191=1.616$ \\
Goodness-of-fit Index (GFI) & $\geq .90$ & .964 \\
Adjusted Goodness-of-fit Index (AGFI) & $\geq .80$ & .953 \\
Absolute badness of fit measure & & \\
Root Mean Square Residual (RMSR/RMR) & $\leq .1$ & .044 \\
Root mean Square Error of Approximation (RMSEA) & $\leq .08$ & .029 \\
Incremental fit measure & & \\
Normed Fit Index (NFI) & $\geq .90$ & .965 \\
Comparative Fit Index (CFI) & $\geq .90$ & .986 \\
Turker Lewis Index (TLI) & $\geq .90$ & .984 \\
Parsimony fit measure & & \\
Parsimony Goodness-of-Fit index (PGFI) & $\geq .50$ & .728 \\
Parsimony Comparative of Fit index (PCFI) & $\geq .50$ & .816 \\
Parsimony Normed of Fit index (PNFI) & $\geq .50$ & .841 \\
\hline
\end{tabular}

Note. Table 3 shows the goodness-of-fit indices for the proposed model against the benchmark (Hair et al., 2010). 


\subsection{Assessing Hypothesized Relationships}

Table 4 and Figures 2 provide a summary of the results for testing the hypotheses and analysing the path co-efficients respectively. Generally, it is evident that all the hypotheses were supported by the data, except H8. In sum, KNMNP and PUMNP explain about $68.6 \%$ of ATTMNP, and ATTMNP and KNMNP together explain about $35.8 \%$ of MNPSEF. Together, the model predicts $50 \%\left(\mathrm{R}^{2}=.50\right)$ of the variations in consumer SINT.

Table 4. Results for hypothesis testing

\begin{tabular}{|c|c|c|c|c|c|c|c|c|}
\hline Hypothesis & Path & & & Std. $\beta$ & S.E. & C.R. & $p$-value & Results \\
\hline 1 & PUMNP & $<---$ & KNMNP & -.178 & .03 & -4.154 & $* * *$ & Supported \\
\hline 2 & ATTMNP & $<---$ & KNMNP & -.067 & .017 & -2.041 & $.041^{*}$ & Supported \\
\hline 3 & MNPSEF & $<---$ & KNMNP & .306 & .027 & 6.866 & $* * *$ & Supported \\
\hline 4 & ATTMNP & $<---$ & PUMNP & .814 & .04 & 15.526 & $* * *$ & Supported \\
\hline 5 & ATTSW & $<---$ & PUMNP & .122 & .045 & 2.542 & $.011^{*}$ & Supported \\
\hline 7 & MNPSEF & $<---$ & ATTMNP & -.453 & .056 & -9.145 & $* * *$ & Supported \\
\hline 8 & ATTSW & $<---$ & MNPSEF & .051 & .053 & 1.043 & .297 & Not Supported \\
\hline 9 & SINT & $<---$ & MNPSEF & .071 & .052 & 2.078 & $.038^{*}$ & Supported \\
\hline 10 & PSC & $<---$ & MNPSEF & -.104 & .043 & -2.277 & $.023 *$ & Supported \\
\hline 11 & SINT & $<---$ & ATTSW & .655 & .068 & 13.474 & $* * *$ & Supported \\
\hline 12 & ATTSW & $<---$ & PSC & .433 & .057 & 8.874 & $* * *$ & Supported \\
\hline 13 & SINT & $<---$ & PSC & .106 & .067 & 2.552 & $.011 *$ & Supported \\
\hline
\end{tabular}

Note. ${ }^{* * *}$ Significant at $.001,{ }^{*}$ Significant at .05, Std. $\beta=$ Standardised regression co-efficient, S.E. $=$ Standard error, $P$-value $=$ significant co-efficients are Maximum Likelihood Estimates, C.R. = Critical Ratio (t-values).

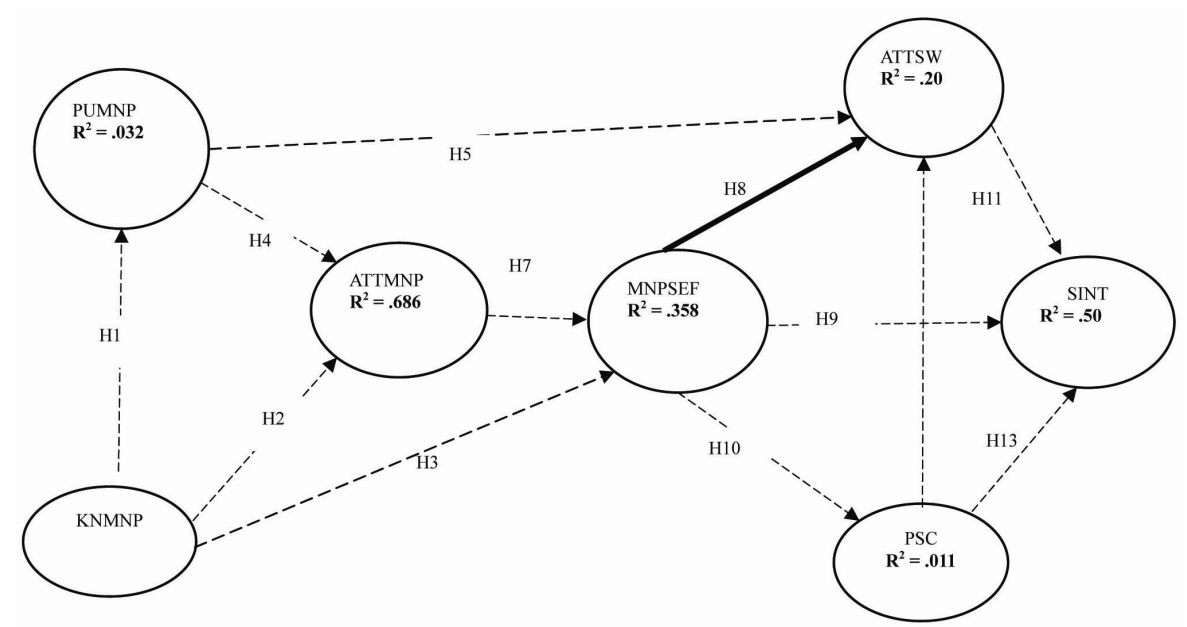

Figure 4. Assessment of hypothesized relationships

Note. Hypothesis H6 representing relationship between PPC and ATTMNP was removed due to construct validity issues; broken lines denote significant relationships (H1-H18, except H8) and unbroken lines denotes insignificant relationships (H8).

\section{Discussion of Findings and Implications to Theory}

The overarching purpose of this study was to assess the extent to which MNP adoption factors influence consumer switching in an emerging economy context. The study extends the adoption of innovations to the telecommunication industry in developing countries, and advances our knowledge on the effects of external business environment variables such as the MNP implementation on consumer behaviour.

To address the first objective of the present study, four factors were found to influence the adoption of MNP policy. These four factors are consumer knowledge of MNP, perceived usefulness of MNP, attitude towards MNP and MNP-induced self-efficacy. The influence of consumer knowledge on their acceptance of service brands and adoption of new technology and innovation has long been established in the marketing and consumer behaviour literature. Thus, the findings confirm numerous studies (e.g., Rogers, 1962, 2003; Rogers, 2003; Cordell, 1997; Huang, Hsieh, \& Chang 2011; Marcketti \& Shelley, 2009) that consumers' knowledge plays a key and leading 
role, as an important starting point, in their acceptance and use of technological innovation in the telecommunication industry.

This study also confirms the findings of numerous studies that perceived usefulness is a fundamental factor that drives consumer attitude towards the acceptance, adoption or use of new technology and innovations (Davis, Bagozzi, \& Warshaw, 1989; Moore \& Benbasat, 1991; Rogers, 2003; Venkatesh, Morris, Davis, \& Davis, 2003; Venkatesh, Thong, James, \& Xu, 2012). Moreover, the study found that consumer attitude towards MNP is fundamentally formed from consumer perceived usefulness and depth of consumer knowledge of the policy, and that perceived usefulness contributes about $67 \%$ of attitude towards MNP adoption.

Furthermore, attitude was found to be a strong predictor of self-efficacy. However strong consumer self-efficacy to adopt MNP is, if they have unfavourable attitude towards MNP, their belief in their ability to switch and therefore adopt MNP will be negatively affected. This underscores the importance of favourable attitude in consumer adoption of MNP and therefore, their porting behaviour; this is consistent with much of the consumer behaviour literature (Ajzen \& Fishbein, 2000, 2005; Liu, Liao, \& Peng, 2005; Park, 2009, Venkatesh, Morris, Davis, \& Davis, 2003; Venkatesh, Thong, James, \& Xu, 2012; Davis, Bagozzi, \& Warshaw, 1989; Moore \& Benbasat, 1991).

For the second and final objective, the study confirms that MNP adoption factors will influence consumer switching behaviour through three important channels: attitude towards switching, MNP-induced self-efficacy (switching efficacy) and perceived switching costs. Specifically, the study found that consumer attitude towards switching is affected by perceived usefulness of MNP, which in turn influences switching intentions. This means that when consumer understand the usefulness of MNP, it could induce positive attitude towards switching as well as a strong switching intention.

Moreover, switching efficacy was a strong predictor of switching intention. The implication is that when consumers have strong belief in their ability to switch through the platform of MNP policy, this will induce a strong willingness to port for the purpose of being able to switch. This confirms many previous studies (e.g., Ajzen, 1991; Conner, Warren, \& Close, 2001; Lam \& Hsu, 2006), but contradicts the findings of Venkatesh, Morris, Davis \& Davis (2003) that self-efficacy is not a direct determinant of intention.

For perceived switching costs channel, switching efficacy was found to negatively influence it. This implies that when consumers efficacy to switch increases as a result of MNP policy, it can reduce switching cost. This confirms that MNP implementation could be an effective way of reducing perceived switching barriers in the telecom industry, thereby achieving one of the Policy's purposes.

Finally, for the attitude towards switching channel, the study found that MNP-induced self-efficacy, perceived usefulness of MNP and perceived switching cost influence it. Thus, perceived switching cost acts to increase switching barrier and therefore negatively influences attitude towards switching, while perceived usefulness and switching efficacy act to induce positive attitude towards switching.

\section{Implications to Management and Industry Regulators}

To practitioners, the paper offers the following implications and recommendations for strategic management and industry regulation. First, the study has identified factors in consumer behaviour that are critical to the adoption of MNP policy at its introduction in mobile telecommunication industry. Management of mobile networks and government agencies would benefit from this study by incorporating these key variables in the design and implementation of strategies for managing MNP policy implementation in telecommunication markets (Peter \& Olson, 1993) in order to achieve the desired results of this innovation.

Second, practitioners in countries that are yet to adopt MNP policy can learn from the findings of the present study by understanding some key consumer behaviour issues that affect the adoption of MNP policy for the purposes of porting, and how to influence consumer behaviour towards adoption of MNP policy.

Third, in countries where MNP is implemented, especially at its introduction stage, managers and governments should focus on developing and enhancing consumer knowledge about MNP policy in general through quality consumer education. Any new innovations require effective dissemination of knowledge for end-users (Roger, 2003). The need for relevant, consistent, timely, consumer oriented and comprehensive quality consumer education on MNP policy becomes the starting point for influence consumer porting behaviour. Therefore, much effort and resources should be committed to consumer education on MNP at different stages of the adoption process. In this regard, the content of such customer education should be relevant, principally focus on, among other things, the rationale of the MNP policy, usefulness of the policy to consumers, the role and responsibilities consumers in the porting process, the benefits of MNP to the telecom industry and the nation as a whole, and the 
channels for reporting complains and issues about the MNP.

Moreover, such consumer education should be consistent in its delivery to consumers about MNP. Stakeholders, especially mobile network operator and government agencies responsible for MNP should, individually and collaboratively, ensure that there is periodic delivery of effective marketing communications on MNP policy through all available advertising and public relations media. Furthermore, the MNP education should be customer oriented and comprehensive. MNP education should reflect consumer interest and preferences regarding the porting process, and targeted at positively influencing three important consumer behaviours, namely, increased consumer curiosity for the adoption of MNP (Loewenstein, 1994), favourable consumer attitude towards porting or MNP, and lowering perceived switching cost.

In addition, consumer education on MNP should be comprehensive enough to highlight likely consumer efforts required in the porting process, authorities and agents responsible for porting and their contacts, offices and customer service centres of mobile operators responsible for assisting customers in completing their porting process, as well as all other relevant information consumer would require to know and have for the porting.

Fourth, for the policy makers such as NCA in Ghana, there is the need to protect consumer interest and right by developing regulations to sanction staff of mobile networks who make attempt to deceive consumers who have little knowledge about MNP. More avenues should be created for consumer complaints and consumer should be informed well about such complaint channels. In view of this, such complaint channels should only include web media such as emails and social networks chats, as well as mobile contact numbers of regulatory offices for consumer complaint purposes.

Fifth, the study implies that practitioners in other countries that have implemented MNP policy can adopt the validated model as an empirical guide in planning and predicting the impact of MNP adoption on consumer switching behaviour towards current service providers.

\section{Limitations and Directions for Future Research}

The main limitation of this present study is that the proposed model did not examine moderating factors that affect consumer adoption such as demographic factors and religious factors, adoption timing characteristics, as well as competitor attraction in the telecom industry. While generalisation may be useful for national policy and strategic management direction, recent research indicate that specific analysis of sub-group differences in adoption research may yield useful results (Arts, Frambacha, \& Bijmolt, 2011). Therefore, future research should include these factors and apply the model in other research contexts to validate the external validity of the proposed model.

Future research should examine cross-context adoption of MNP by consumers at different stages of the MNP adoption life cycle, namely, introduction, growth, maturity and decline stages. As a follow-up on this paper, future research will be conducted by the researchers using the same dataset to perform a comprehensive multi-group analysis investigating differences in MNP adoption factors among different consumer groups.

\section{Conclusion}

In summary, this paper aimed at examining the extent to which MNP adoption can influence switching behaviour in the telecom industry. Drawing on relevant theoretical models in consumer behaviour and technology adoption literature, a theoretical model was developed and validated in the telecommunication industry in a developing country context where MNP policy adoption appears to be at its introduction stage or infancy. The findings indicate that MNP adoption by consumers can influence consumer switching through three main channels: perceived switching costs and attitude towards switching. Typically, these channel factors appear to be attitudinal and belief factors that have been found to play important role in consumer behaviour (Ajzen, and Fishbein, 2000, 2005; Venkatesh, Morris, Davis \& Davis 2003; Venkatesh, Thong, James \& Xu, 2012). In spite of the limitations, the study offers useful theoretical explanation for the link between MNP adoption and consumer behaviour. The managerial implications discussed emphasise the role of consumer education as a key driver of MNP adoption in telecommunication industries, especially in developing countries.

\section{References}

Abdramon, T. O., \& Mejabi, O. V. (2012). Evaluation of Subscriber Attitude to Mobile Number Portability Implementation in Nigeria. Journal of Emerging Trends in Computing and Information Sciences, 3(4), 526-533.

Ajzen, I., \& Fishbein, M. (1980). Understanding attitudes and predicting social behavior. Englewood Cliffs, NJ: Prentice-Hall. 
Ajzen, I., \& Fishbein, M. (1980). Understanding attitudes and predicting social behaviour. Englewood Cliffs, NJ: Prentice Hall.

Ajzen, I., \& Fishbein, M. (2000). Attitudes and the Attitude Behavior Relation: Reasoned and Automatic

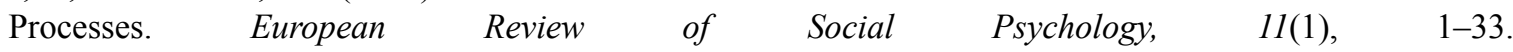
http://dx.doi.org/10.1080/14792779943000116

Ajzen, I., \& Fishbein, M. (2005). The Influence of Attitudes on Behavior. In D. Albarracín, B. T. Johnson, \& M. P. Zanna (Eds.), The Handbook of Attitudes (pp. 173-221). Mahwah, NJ: Erlbaum.

Anderson, J. C., \& Gerbing, D. W. (1988). Structural equation modelling in practice: A review and recommended two-step approach. Psychol. Bull, 103(3), 411-423. http://dx.doi.org/10.1037/0033-2909.103.3.411

Arts, J. W. C., Frambacha, R. T., \& Bijmolt, T. H. A. (2011). Generalizations on consumer innovation adoption: Ameta-analysis on drivers of intention and behavior. Intern. J. of Research in Marketing, 28, 134-144. http://dx.doi.org/10.1016/j.jiresmar.2010.11.002

Bagozzi, R. P., \& Yi, Y. (1988). On the evaluation of structural equation models. Journal of the Academy of Marketing Science, 16, 74-94. http://dx.doi.org/10.1007/BF02723327

Bagozzi, R. P., (2007). The legacy of the technology acceptance model and a proposal for a paradigm shift. Journal of the Association for Information Systems, 8(4), 244-254.

Bandura, A. (1982). Self-efficacy mechanism in human agency. American Psychologist, 37, 122-147. http://dx.doi.org/10.1037/0003-066X.37.2.122

Bansal, H. S., \& Taylor, S. F. (1999). The service provider switching model (SPSM): A model of consumer switching behavior in the services industry. Journal of Service Research, 21, 200-218. http://dx.doi.org/10.1177/109467059922007

Bansal, H. S., Irving, P. G., \& Taylor, S. F. (2004). A three component model of customer commitment to service provider. Journal of the Academy of Marketing Science, 32(3), 234-250. http://dx.doi.org/10.1177/0092070304263332

Bansal, H. S., Taylor, S. F., \& James, Y. St. (2005). "Migrating” to New Service Providers: Toward a Unifying Framework of Consumers' Switching Behaviors. Journal of the Academy of Marketing Science, 33(1), 96-115. http://dx.doi.org/10.1177/0092070304267928

Barroso, C., \& Picón, A. (2012). Multi-dimensional analysis of perceived switching costs. Industrial Marketing Management, 41(3), 531-543. http://dx.doi.org/10.1016/j.indmarman.2011.06.020

Buehler, S., \& Haucap, J. (2004). Mobile Numbering and Number Portability in Ireland. A report to the ODTR, Ovum: London. Journal of Industry, Competition and Trade, 4(3), 223-238. http://dx.doi.org/10.1023/B:JICT.0000047299.13443.5a

Clemes, M. D., Gan, C., \& Ren, M. (2011). Synthesizing the Effects of Service Quality, Value, and Customer Satisfaction on Behavioral Intentions in the Motel Industry: An Empirical Analysis. Journal of Hospitalityand Tourism Research, 35(4), 530-568. http://dx.doi.org/10.1177/1096348010382239

Conner, M., Warren, R., \& Close, S. (2001). Alcohol consumption and the theory of planned behavior: An examination of the cognitive mediation of past behavior. Journal of Applied Social Psychology, 29(8), 1676-1704. http://dx.doi.org/10.1111/j.1559-1816.1999.tb02046.x

Cordell, V. V. (1997). Consumer Knowledge Measures as Predictors in Product Evaluation. Psychology \& Marketing, 14 , 241-260. http://dx.doi.org/10.1002/(SICI)1520-6793(199705)14:3<241::AID-MAR3>3.0.CO;2-B

Danaher, P. J., \& Haddrell, V. (1996). A comparison of question scales used for measuring customer satisfaction. International Journal of Service Industry Management, 7(4), 4-26. http://dx.doi.org/10.1108/09564239610129922

Davis, F. D., Bagozzi, R. P., \& Warshaw, P. R. (1989). User acceptance of computer technology: A comparison of two theoretical models. Management Science, 35(8), 982-1003. http://dx.doi.org/10.1287/mnsc.35.8.982

DeVellis, R. F. (2003). Scale development: theory and applications (2nd ed.). Newbury Park, CA: Sage.

Farrell, A. M. (2010). Insufficient discriminant validity: A comment on Bove, Pervan, Beatty, and Shiu (2009). Journal of Business Research, 63, 324-327. http://dx.doi.org/10.1016/j.jbusres.2009.05.003 
Fishbein, M., \& Ajzen, I. (1975). Belief, attitude, intention, and behavior: An introduction to theory and research. Reading, MA: Addison-Wesley.

Fornell, C., \& Larcker, D. F. (1981). Evaluating structural equation models with unobservable variables and measurement error. Journal of Marketing Research, 18, 39-50. http://dx.doi.org/10.2307/3151312

Gans, J. S., \& King, S. P. (2000). Mobile network competition, customer ignorance and fixed-to mobile call prices. Inform. Econ. Policy, 12, 301-327. http://dx.doi.org/10.1016/S0167-6245(00)00007-X

Gera, R. (2011). Modelling the service antecedents of favourable and unfavourable behavior intentions in life insurance services in India. An SEM study. International Journal of Quality and Service Sciences, 3(2), 225-242. http://dx.doi.org/10.1108/17566691111146113

Gerrard, P., \& Cunningham, J. B. (2004). Consumer switching behavior in the Asian banking market. Journal of Services Marketing, 18, 215-223. http://dx.doi.org/10.1108/08876040410536512

Hair, J. F., Black, W. C., Babin, B. J., \& Anderson, R. E. (2010). Multivariate Data Analysis. Englewood Cliffs, NJ: Prentice Hall.

Hoehle, H., \& Scornavacca, E., \& Huff, S. (2012). Three decades of research on consumer adoption and utilization of electronic banking channels: A literature analysis. Decision Support Systems, 54, 122-132. http://dx.doi.org/10.1016/j.dss.2012.04.010

Huang, L. Y., Hsieh, Y. J., \& Chang, S. E. (2011). The effect of consumer innovativeness on adoption of location-based services. Review of Global Management and Service Science, 1(1), 17-31.

Keaveney, S. M. (1995). Customer switching behavior in service industries: An explorative study. Journal of Marketing, 59(2), 71-82. http://dx.doi.org/10.2307/1252074

Kidwell, B., \& Jewell, R. D. (2003). An examination of perceived behavioral control: Internal and external influences on intention. Psychology \& Marketing, 20, 625-642. http://dx.doi.org/10.1002/mar.10089

King, T. R. (1991). Advertising: Putting forth the art of holding back. Wall Street Journal, p. 4.

Lam, T., \& Hsu, C. H. C. (2006). Predicting behavioral intention of choosing a travel destination. Tourism Management, 27, 589-599. http://dx.doi.org/10.1016/j.tourman.2005.02.003

Larkotey, W. O., Ansong, E. D., Damoah, D., Abandoh-Sam, J. (2012). Mobile Number Portability in Developing Countries: Its successes and failures. Case Study-West African Sub-Region. International Journal of Societal Applications of Computer Science, 1(1), 44-55.

Lee, M. K. O., Cheung, C. M. K., \& Chen, Z. (2005). Acceptance of Internet-based learning medium: The role of extrinsic and intrinsic motivation. Information \& Management, 42, 1095-1104. http://dx.doi.org/10.1016/j.im.2003.10.007

Leem, J., \& Lim, B. (2007). The current status of e-learning and strategies to enhance educational competitiveness in Korean higher education. The International Review of Research in Open and Distance Learning, $\quad 8(1) . \quad 1-18 . \quad$ Retrieved April 30, 2007, from http://www.irrodl.org/index.php/irrodl/article/viewArticle/380/763

Legris, P., Ingham, J., \& Collerette, P. (2003). Why do people use information technology? A critical review of the technology acceptance model. Information \& Management, 40, 191-204. http://dx.doi.org/10.1016/S0378-7206(01)00143-4

Lin, J. C., \& Lu, H. (2000). Towards an understanding of the behavioral intention to use a Web Site. International Journal of Information Management, 20, 197-208. http://dx.doi.org/10.1016/S0268-4012(00)00005-0

Lin, Y., Chlamtac, I., \& Yu, H. (2003). Mobile number portability. IEEE Network, 17, 8-16. http://dx.doi.org/10.1109/MNET.2003.1233913

Liu, S., Liao, H., \& Peng, C. (2005). Applying the technology acceptance model and flow theory to online e-learning users' acceptance behavior. Issues in Information Systems, 6(2), 175-181.

Loewenstein, G. (1994). The Psychology of Curiosity: A Review and Reinterpretation. Psychological Bulletin, 116(1), 75-98. http://dx.doi.org/10.1037/0033-2909.116.1.75

Marcketti, S. B., \& Shelley, M. C. (2009). Consumer Concern, Knowledge and Attitude towards Counterfeit Apparel Products. International, Journal of Consumer Studies, 33, 327-337. http://dx.doi.org/10.1111/j.1470-6431.2009.00748.x 
National Communication Authority. (2012). Mobile Number Portability in Ghana—First Year Report—July 18, 2012. Retrieved from http://nca.org.gh/downloads/MNP_at_2Years_Report_3rd_September_2013.pdf

National Communication Authority. (2013). Mobile Number Portability in Ghana-Second Year Report—July31, 2013. Retrieved from http://nca.org.gh/downloads/MNP_at_2Years_Report_3rd_September_2013.pdf

Odunaike, S. A. (2010). The Impact of Mobile Number Portability on TUT students On-line Connectivity. Information Systems Educators Conference, 2010 ISECON Proceedings Nashville Tennessee, USA.

Oftel. (1997). Economic Evaluation of Number Portability in the UK Mobile Telephony Market, Oftel. London, July 1997.

Ovum. (2000). Mobile Numbering and Number Portability in Ireland. A Report to the ODTR, Ovum. London, October 2000.

Park, S. Y. (2009). An Analysis of the Technology Acceptance Model in Understanding University Students' Behavioral Intention to Use e-Learning. Educational Technology \& Society, 12(3), 150-162.

Peter, J. P., \& Olson, J. C. (1993). Consumer behavior and marketing strategy (3rd ed.). Chicago: Irwin.

Prins, R., Verhoef, C. P., \& Franses, P. H. (2009). The impact of adoption timing on new service usage and early disadoption. Intern. J. of Research in Marketing, 26, 304-313. http://dx.doi.org/10.1016/j.ijresmar.2009.07.002

Razali, N. M., \& Wah, Y. B. (2011). Power comparisons of Shapiro-Wilk, Kolmogorov Smirnov, Lilliefors and Anderson-Darling tests. Journal of Statistical Modelling and Analytics, 2(1), 21-33.

Reinke, T. H. (1998). Local Number portability and local loop competition. Telecommunications Policy, 22(1), 73-87. http://dx.doi.org/10.1016/S0308-5961(97)00058-X

Rogers, E. M. (1962). Diffusion of Innovations. New York The Free Press.

Rogers, E. M. (2003). Diffusion of innovations (5th ed.). New York, NY: Free Press.

Roos, I., Edvardsson, B., \& Gustafsson, A. (2004). Customer Switching Patterns in Competitive and Noncompetitive Service Industries. Journal of Service Research, 6, 256. http://dx.doi.org/10.1177/1094670503255850

Suthar, B. K., Sharma, K. J., \& Gwal, A. (2012). A study on Consumer behaviour after mobile number portability with reference to Gujarat Telecom Circle. BAUDDHIK, 3(2), 1-7.

Tiamiyu, O. A., \& Mejabi, O. V. (2012). Evaluation of Subscriber Attitude to Mobile Number Portability Implementation in Nigeria. Journal of Emerging Trends in Computing and Information Sciences, 3(4), 526-533.

Venkatesh, V. (2000). Determinants of Perceived Ease of Use: Integrating Perceived Behavioral Control, Computer Anxiety and Enjoyment into the Technology Acceptance Model. Information Systems Research, 11(4), 342-365. http://dx.doi.org/10.1287/isre.11.4.342.11872

Venkatesh, V., \& Davis, F. D. (2000). A Theoretical Extension of the Technology Acceptance Model: Four Longitudinal Field Studies. Management Science, 45(2), 186-204. http://dx.doi.org/10.1287/mnsc.46.2.186.11926

Venkatesh, V., Morris, M. G., Davis, G. B., \& Davis, F. D. (2003). User acceptance of information technology: toward a unified view. MIS Quarterly, 27(3), 425-478.

Venkatesh, V., Thong, J. Y. L., \& Xu, X. (2012). Consumer acceptance and use of information technology: extending the unified theory of acceptance and use of technology. MIS Quarterly, 36(1), 157-178.

Wright, J. (2002). Access pricing under competition: an application to cellular networks. J. Ind. Eco., 50, 289-31. http://dx.doi.org/10.1111/1467-6451.00178

Yamane, T. (1967). Statistics: an introductory analysis. New York: Harper and Row.

Zhang, K. Z. K., Cheung, C. M. K., \& Lee, M. K. O. (2012). Online service switching behavior: The case of blog service providers. Journal of Electronic Commerce Research, 13(3), 184-197. 


\section{Copyrights}

Copyright for this article is retained by the author(s), with first publication rights granted to the journal.

This is an open-access article distributed under the terms and conditions of the Creative Commons Attribution license (http://creativecommons.org/licenses/by/3.0/). 